[Published in: D. Berti, A. Good \& G. Tarabout (eds), Of Doubt and Proof. Ritual and Legal Practices of Judgment. 2015. Farnham / Abingdon, Ashgate / Routledge, pp. 19-38]

\title{
/p. 19/
}

\section{Chapter 1: Technicalities of Doubting: Temple Consultations and Criminal Trials in India}

Daniela Berti (CNRS, Centre for Himalayan Studies)

The notion of doubt has often been addressed in anthropology in relation to the question of belief. Anthropologists started to question the relevance of using the Western category of 'belief' to describe the practices and attitudes of the people they studied, notably after the publication of the critical approach developed by Needham (1972). By underlining the association generally made between belief and conscience, some authors preferred to replace the notion with other terms less linked to the idea of individual conviction, such as representation (Lenclud 1990; Pouillon 1993; Hamayon 2006; Schlemmer 2009); others started to consider doubt and scepticism as crucial aspects of ritual practices that had erroneously been underreported in fieldwork accounts (Boyer 1990; Beatty 1999; Rappaport 1999). ${ }^{1}$

A debate parallel to that about belief then developed around the notion of reflexivity. In his introduction to a journal special issue, Højbjerg (2002) focuses on 'reflexive attitudes' such as doubt, incertitude or the 'do as if' adopted by people taking part in religious practices. Here reflexivity is intended not only in the sense that ritual actions are submitted to public debate among the audience or to diverging comments from the ritual specialists themselves. It is also considered as being the result of the organizational form of ritual

\footnotetext{
${ }^{1}$ A similar debate has developed in the field of history. Veyne (1992), for example, dealt with the question of belief in terms of 'programme de vérité'.
} 
action, including ritual language and the modes of transmission of religious ideas (Severi 2002). In other words, reflexive attitudes are not only part of a discursive register. They may also be devices completely integrated into the rules used in a specific institutional context of interaction.

In line with this perspective, I deal in this chapter with practices of doubting in two institutional settings found in the Himachal Pradesh region of the Indian Himalayas, which are both concerned with the process of judging. ${ }^{2}$ My aim is not to investigate personal or cognitive experiences of doubting. By taking doubt as a matter of practice and technique, my aim is to see how doubting is managed and resolved in reference to decision-making processes. First of all I talk about temple /p. 20/ consultations during which village deities, through their institutional mediums, are asked to arbitrate local conflicts and to give their verdict on people's misconduct. These ritual procedures are then compared to the ways in which the techniques of doubting and proving are used in Indian criminal trials as well as in judges' rulings.

Although temple mediums and judges may not appear to have anything in common, they do in fact share some similarities: both arbitrate cases, interpret or establish 'facts' and 'truth', and pronounce judgments and verdicts. In one case the arbitrator is a god's medium who speaks on behalf of a village deity; in the other he is a professional judge who speaks in the name of the law.

In both contexts - ritual and judicial - the verdict is preceded by processes to either quell or develop any doubt, but in ways that are almost totally opposite in the two cases. With regard to the deity's medium, the doubt that must be expressed or removed is, above all, the doubt that the person consulting the deity may have about the way the deity interprets their problem - because this interpretation may clash with their perception of the facts. However, given that the deity is considered to already 'know the truth', the doubt in question concerns whether the medium is really speaking on behalf of the deity and not on his own behalf.

${ }^{2}$ Research leading to this chapter was funded by the French National Research Agency (ANR) as part of the programme 'Just-India: A Joint Programme on Justice and Governance in India and South Asia' (http://just-india.net) (ANR-08-GOUV-064). 
By contrast, in the case of a judicial trial, it is the judge's doubt that has to be disproved or confirmed, and during the trial the lawyer for the accused and the prosecutor have to produce a set of evidence and arguments in order to either sow or remove any doubt in the judge's mind. Moreover, in his final ruling, the judge's personal opinion about the facts has to comply with the way the notions of doubt and proof are used in legal codes and judicial procedures.

\section{Consulting the Village God}

I will first present this practice of doubting and proving in the context of medium consultations. At the time of ritual consultations (deopuchna) a village deity is made part of an interactional setting within which its presence is enacted by its human medium (gur or chela). ${ }^{3}$ The medium's authority comes from the deity by whom he is supposed to have been chosen, although this divine selection has to be officially and publicly recognized during a special village ceremony. Once initiated, a medium has the duty to 'presentify' (Vernant 1985) the deity in all ritual festivals and also to hold regular consultations at people's request. ${ }^{4}$ In exchange for his service as a medium he may be granted some tenancy rights over/p. 21/ the deity's property or he may receive part of the offerings made by those who come for a consultation. Consulting a god is thus a highly institutionalized ritual context where the deity's manifestation in the medium's body, as well as the interaction which takes place between the deity and the people, is regulated by a series of procedures and formalized ritual techniques.

Moreover, many of those who attend these consultations also feel that they have institutional links with the deity, either because they have received some of the god's land in exchange for their services at the temple (such as musicians, priests or administrators) or simply because they live within the area (har) over which the deity is

\footnotetext{
3 The fieldwork material analysed here has been collected in different villages situated in Kullu district. The official language of the area is Hindi even though in rural areas, especially in the context of temple consultations, people often used Pahari, a local dialect.

4 The expression refers to the French word 'présentifier' used by J.P. Vernant (1985) to indicate the action or process by which an entity that belongs to the invisible world takes form in the human world.
} 
considered to exercise its power. The multiple names people use to address the deity during a consultation - Maharaj (king), Bhagvan/Bhagvati (god/goddess) Mata (mother) or even Malik (landowner) - indicate the multiple registers on which the relationship between people and the deity is constructed. These ritual links and obligations have historical roots in the royal past as many of these deities received land donations from various kings of the region and were somehow considered as local rulers (Berti 2009). Their public role was recognized during the colonial period by the British administrators, who officially declared many village deities of the region owners of the land by recognizing the deity's juristic 'personality' (Sontheimer 1964). The legal existence of a deity continues to be recognized in the post-colonial state to the point that a god may become the main petitioner in a court case (Malik 2010; Berti 2012a; Clementin-Ojha 2013).

Interestingly, in a bureaucratic setting - for example before a judge or Deputy Commissioner - a deity is represented by the temple administrator since the medium plays no part in it. On the contrary, at village level the medium is the main means of accessing the deity. ${ }^{5}$ Through the medium the deity is directly questioned not only about settling personal or family problems but about its opinion on any major decision to be taken at village level.

Disputes among villagers are regularly brought before the deity who is asked to pronounce judgment and to propose a compromise between the parties. The deity's verdict may sometimes even take a form of competition with the court of law when those consulting the deity are involved in an ongoing court case. This judicial role of the deity is specified during the ritual when the medium, when speaking on behalf of the deity, may say 'The court is mine, justice is mine' (Berti 2012a). ${ }^{6}$

During the consultation, the medium, who often belongs to a low-status caste, is addressed as if he were the deity, and what he says is considered to come directly from the deity. This is true in principle, at least. In practice, consulting a deity always involves undertaking a process of doubting, which is induced by the ritual procedure. As I will show in the next section, mediums have recourse to various /p. 22/

\footnotetext{
${ }^{5}$ In Tamil Nadu it is the temple trustee rather than the administrator who represents the deity in court (Anthony Good, personal communication).

${ }^{6}$ For the region of Garhwal, see also Malik (2010).
} 
techniques to deal with doubt, some of which are commonly used by all the mediums in the region, while others are specific to a particular deity.

\section{The Presumption of Doubt: 'Distributing Rice'}

In ritual consultation, the possibility that people doubt what the medium $^{7}$ tells them is fully acknowledged and the ritual procedure includes specific techniques of contestation and verification. Some of these techniques are codified in the gestures that the medium performs at each consultation. For example, at the very beginning of the séance, immediately after the deity has been ritually embodied in the medium, the latter takes out a lock of hair from his forehead. This gesture is described as a kind of promise he makes to speak 'the truth', which means that he will not speak for himself; he will talk only if and when the deity, as people say, 'comes' (ata he) into his body.

The general discourse is, in fact, that the deity's presence in the medium is intermittent; it comes and goes - an idea that in itself leaves room for possibly doubting what the medium is saying. The gesture is presented as a sort of oath that the medium has to take before speaking: just like the judge who asks the witnesses to swear that they will speak the truth before the court, here the deity itself is said to ask its own medium to swear that he will not speak for himself, that he will be merely a vehicle for the deity's speech.

At the very beginning, before the individual consultation begins, the medium starts by distributing a small handful of rice to each of those taking part in the consultation. This is another systematic, codified procedure that is followed every time a consultation is held. The one who receives the grains must count them and see if there is an odd or even number. If it is an odd number, it means that the person is 'of one mind', that he does not have any doubts, at least at this stage. On the other hand, if it is an even number

\footnotetext{
${ }^{7}$ Here we enter an area of linguistic fluidity for the anthropological description. If we use the term 'medium' we adopt an analytical point of view; if we use the word 'deity' we take the point of view of those who consult, though we omit the fact that the people themselves may think that it is the medium who is speaking, not the deity. Here I will use the word deity or medium according to which point of view I want to stress.
} 
it means that he has some doubt. For example, the expression 'char vichar' may be used among the audience, which means that if one has four grains this shows that the person has some thoughts. The person, or the other attendants, may then react by addressing the deity, for example with the following words: 'O Maharaj! Why these thoughts? We don't want any thoughts. We honour you'. In order to get rid of these thoughts, the person who is supposed to doubt has to throw away the grains and ask the medium to give him or her another handful of rice for as long as it takes to obtain an odd number.

This kind of interaction shows, on the one hand, how the person who is consulting the deity is considered to be somehow unaware of the fact that he doubts /p. 23/ because the 'thoughts' (vichar) are presented as being independent of the person's will. In fact it is the deity, not the person, who is asked by the audience to eliminate these vichar. An even number of grains of rice is in fact treated by people as a bad omen or as a negative presence rather than as indicative of the person's mental attitude. On the other hand, the fact that the person has to throw the grains until he gets an odd number shows that the procedure of taking the grains of rice is meant not only 'to check' whether the person harbours some doubts, but 'to make' him not have any. ${ }^{8}$

\section{Interactional Doubt: 'Giving Rice' and 'Ore Pogre'}

Once this collective process of eliminating the vichar is complete, interactions take place at a more individual level. The first person to be heard by the deity is again given a handful of rice and they again check the number. This giving rice and counting the grains may be repeated throughout the consultation, which may last some time, especially if the case proves to be serious.

In some cases, during the verbal interactions, the person consulting the deity appears to challenge what the deity says or to propose a different explanation of the problem from the one proposed by the deity. In one particular case, for example, a woman, who was well-known to the medium, ${ }^{9}$ did not agree with what the deity was

\footnotetext{
${ }^{8}$ On this topic, see Hamayon (2006) for shamanic procedures of divination.

${ }^{9}$ The medium usually knows the person who is consulting the deity, especially when the person is from the same village.
} 
saying about her situation. She was given rice many times but it was always an odd number - which meant that the woman had no doubts. She eventually counted an even number and threw away the rice because that meant that she did have some doubts. The medium then stopped giving her rice and started reproaching her for questioning what he (the deity) said. This case shows how, although the rice is meant to check whether the person has some doubts, it may be used by the medium to somehow accuse the person of not telling the truth and of challenging the deity's verdict.

Another interactional form of doubting is the so-called ore pogre which literally means 'round stones' and refers to a procedure by which the person consulting the deity has to arrange three stones in the shape of a triangle on the floor. They have to mentally associate each stone with a possible cause of the problem. One stone may be associated, for example, with the idea that the person's problem is due to an act of witchcraft; the second stone with the idea that what has happened to them is due to some punishment inflicted by a deity; and the third stone with the idea that the problem is due to some planetary movement. Once the person has made this mental association, the medium has to choose the stone to indicate the exact cause.

/p. 24/

During the consultation, the medium may ask the person 'to put ore pogre' in different situations. He may do this when he considers that the person is - as the medium says - 'in two minds', meaning that he has some doubt. The request to put ore pogre appears to come from the deity itself and not from the medium. This is made explicit in ritual interactions as the person doing ore pogre continues to address the deity. In fact, up until the end of the consultation the possibility that the 'medium' is acting on his own behalf is never openly evoked by the audience. By contrast, it may be paradoxically suggested by the medium himself who, speaking on behalf of the deity, may say to the person 'If you don't believe my patru ('recipient', that is the medium), put ore pogre and I will tell you myself'. Although in ore pogre the medium has to select the stone, the procedure is presented as being somehow less dependent on the medium-as-a-man than the reply that he gives verbally during the consultation. The fact that a reply has been given through ore pogre is in fact referred to by people as 'proof' that the reply is 'true'. 
Sometimes ore pogre is recommended by the medium as a reaction to a person's behaviour. For example, when the deity starts to say that a person's problem is not due to any punishment, that it is simply due to difficult times, or to some inauspicious planets, the person may say 'O Bhagvan, why don't you want to tell me what has happened?' The medium then asks the person to put ore pogre. To start with, the person usually refuses to do this because they do not want to challenge the deity. Thus, they may begin to say 'No, deity, I don't want to defy you, I don't want any confrontation with you. Tell me in your own words [that is, through the medium]'. In such cases, people nearby may start asking the person to put ore pogre as though they want to convince them to accept - which the person eventually does.

Man: We don't want to put ore pogre.

Medium: first of all you must put ore pogre and then I will explain to you and I will fulfil your request.

Man: Eh deity, tell us with your own words, we don't want to put ore pogre.

Medium: you put ore pogre and I will tell you the outcome! Put ore pogre!

Other people: You must say it like that [verbally]! (field notes, Jagatsukh, 1995)

In some cases, the test with the three stones is a way for the person to check what the medium has already said to them verbally; at the same time it may be used by the medium to negotiate the person's reply, and even to adjust or to change his initial reply as a consequence of the interaction he has had with the person. For example, in one case the medium told a woman that she was under a bad planetary influence (din dasha) but the woman did not like the idea of simply being affected /p. 25/ by a bad planet as this was not regarded as a real explanation for the problem. She began to cry, showing that she was not satisfied with the reply, so the medium told her: 'Put ore pogre and satisfy your own mind. [See] if there are some bad planets or if there is 
a bhut [ghost] sent by someone to harm you. Put ore pogre and then I will tell you myself!, ${ }^{10}$

The woman then put ore pogre and when the medium selected a stone, she let out a cry of joy, which implicitly indicated that the stone chosen was not the one with which she associated bad planets. The medium, speaking on behalf of the deity, then told her, 'There is a bhut. Do you see now?', and thus he changed his interpretation of the woman's problem. The woman's satisfaction was clearly evident: having an enemy to fight is more reassuring than believing that one's problems are due to inauspicious planets where it is more difficult to ritually intervene.

The fact that the interpretation of the problem may change during the dialogue is generally accepted. One formula frequently used by the medium during the consultation is 'you're in two minds [you doubt], I have seven speeches'. In other cases, however, the formula used by the medium is 'one word, one weight, one balance', by which the medium confirms what he - that is the deity - had previously said.

In cases where the medium selects a stone that corresponds to a reply that is not what the person would have liked to hear, the reaction may vary: the person may think that the medium is speaking for himself or that the deity does not want to tell them the truth; or they are no longer certain about the association they had made and they want to repeat the procedure; or they may just say that they don't want to find out through ore pogre but they want the deity to speak to them directly (that is, through his medium).

It must also be said that the way in which the medium selects the stone may be more or less ambiguous: sometimes he touches the stone with the ritual bell, throwing aside the selected stone; sometimes he pushes away two stones with the bell, which may suggest that he has chosen the third stone. Finally, even if the medium selects what the person thinks is a good reply, the person may carry on having some doubts. They then have to repeat ore pogre two or three more times.

Like other ritual contexts reported in the literature, the case of medium consultations analysed here shows how the expression of doubt is internal to the ritual logic. We have seen how, for example, it is by speaking as the deity that the medium requests the person to

\footnotetext{
${ }^{10}$ Bhut (here ghosts, or minor deities) are often considered to be sent by a witch who takes the bhut under their control and orders them to harm the person physically or to upset their family relations.
} 
express or to solve his or her doubt. In some cases this even creates a sort of linguistic paradox with the medium speaking as the deity who explicitly says to the people 'If you do not believe my medium [patru, that is, recipient] then put ore pogre and I will tell you myself'. This shows how the ritual action not only presumes the manifestation of the deity, but may /p. 26/ also challenge it or be performed in order to test the effectiveness of the deity's power (Severi 2002). In the context of the deity consultations analysed here this may even end up creating a kind of short circuit as, for example, when the deity, somehow challenging its own existence, says during the séance 'If you honour me, I am a god, otherwise I am a piece of stone'.

On the other hand, the analysis of the procedure shows how in the context of ritual consultations doubting does not appear to be related only to the question of belief. Instead, it is a way for people to become involved in the interpretative process and for the medium to reinforce his verdict or, on the contrary, to change it. It enables the medium as well as the person consulting the deity to adjust their respective interpretation and comprehension of the situation submitted to the consultation. Doubting in this context is in fact a creative aspect of the interaction, a communicative technique that leaves room for discussion or contestation.

\section{Law Courts and Criminal Proceedings}

I will now compare this practice of doubting in this institutionalized ritual setting with the one used in judicial settings (in the same region) and especially with the way doubt is expressed and formulated during a trial as well as in judges' rulings. Unlike in ritual consultations, where doubt expressed during the procedure comes mostly from the person consulting the deity, in the case of a trial, the doubt that must be refuted or confirmed is doubt in the judge's mind about the guilt of the accused.

In his work on the theological roots of the criminal trial, Whitman (2008) argues that 'reasonable doubt' is to be seen as a vestige of a very widespread pre-modern anxiety about judging and punishing. The author shows how the original function of reasonable doubt was not, as it is today, to protect the accused, but to protect jurors against the potential mortal sin of convicting an innocent 
defendant. The rule of 'reasonable doubt' was, he argues, a 'technique of moral comfort', aimed at protecting the judge from damnation (Whitman 2008: 6). Although in India the religious dangers attendant upon judging were mentioned in Sanskrit texts in the early centuries of the Common Era (Granoff 2010), by the time Western criminal procedures were introduced during the colonial period, they were in no way associated with these medieval religious concerns and were perceived as completely secularized techniques. Some of the practices adopted during colonial times, such as the jury trial, were even abolished soon after Independence, and the absence of the jury trial does not seem to have generated any particular religious anxiety about the judge's salvation in the next life. The procedure followed in India during a trial therefore no longer has any obvious link with Christian or Brahmanical religious concerns, and violations of rules or offences are not sanctioned according to religious precepts but according to sections of the Civil or Penal Code (Berti 2012a).

/p. 27/

As in other adversarial systems, here again the criminal trial takes the form of a battle between two (supposedly) equal parties: the prosecution, which attempts to prove its case beyond reasonable doubt, and the defence, which seeks to undermine the prosecution's case and to create reasonable doubt. As Lea (2006) notes regarding the English procedure, the task of the defence is not to prove the innocence of the defendant but to prevent the prosecution from proving their guilt.

Unlike in the British criminal system, the trial judge in India is completely alone in deciding the case. The absence of a jury often leads the judge, the prosecutor and the lawyers to discuss technical points such as procedural constraints of the investigations, legal sections and contradictions between witnesses' versions. The witnesses, especially when they are from rural areas and with no knowledge of English, are unable to follow interactions of this kind, which constantly shift from the vernacular to English. These may also turn out to be rather animated discussions between the judge and the attorneys, with one constantly interrupting the other.

The absence of a popular jury does indeed influence the way a trial is performed. All interactions take place very close to the judge, who follows the verbal exchanges with the file in front of him. Judges often take an active part in the interactions by putting many questions to witnesses, especially when they think that the prosecutor is not 
asking them the relevant questions. It is also through the judge that witnesses' replies are put into official writing. After each interaction in Hindi the judge translates and dictates to the stenographer the content of the corresponding question-reply, and formulates the sentences in the first person as if the witness were actually dictating.

This process of official transcription, which in cross-examination is sometimes taken over by the defence lawyer, includes conventional formulas which allow doubt to be expressed and, even more importantly, to be somehow suggested in the record. We will now see how, during the different stages in the case, doubt is expressed and solved.

\section{Adversarial Doubting: Hostile Witnesses and Cross-examination}

In Indian judicial procedures many verbal and oral techniques are available in order to express doubt in a codified way. One of these techniques is linked to the practice of declaring a witness 'hostile'. This especially happens in relation to prosecution witnesses, who are called by the prosecutor to back the accusations. At the time of the trial, prosecution witnesses are asked to repeat before the judge what they previously stated to the police during the investigations. These witnesses are first questioned by the prosecutor (as well as by the judge) according to the rules that apply to the examination-in-chief, where questions are left open. However, it very often happens that the witnesses' replies contradict their previous statement, the written version of which is included in the police report. When this happens, the witness is accused of not telling the truth. This follows an extremely /p. 28/ codified procedure which consists in dictating in English to the stenographer a sentence of the following kind:

At this stage Learned Public Prosecutor has stated that witness is trying to suppress the truth. As such request is made to cross examine the witness, which is considered and allowed. ${ }^{11}$

Since the sentence is dictated in English, it is not usually understood by the witness who is therefore not aware that he has just

\footnotetext{
${ }^{11}$ In fact, as in the example below, this sentence is often dictated on the initiative of the judge but on behalf of the prosecutor.
} 
been 'officially' accused of telling a lie. However, from a procedural point of view, after this sentence has been dictated, the questions are put to the witness according to the rules that apply to cross-examination. He will be systematically confronted with his previous statement which is referred to after every question. To each question the witness has to reply yes or no. The content of the question is then transcribed and translated by adding the formula 'It is incorrect that ...' or 'I have not stated that ...' in the event where he replies no and 'It is correct that ...' in the case where he replies affirmatively.

When he replies in the negative, the English transcription of the reply is followed by the sentence 'Confronted with portion [reference to the paragraphs] of the statement ... in which it is so recorded'. Long paragraphs of the police report may therefore be referred to in court records by using the negative formula 'it is incorrect that ...' when quoting from it, which aims at underlining that the witness has changed his previous version and he is thus lying before the court.

Let us look at an example where, during the trial, a father who had previously accused his daughter's in-laws of being responsible for his daughter's suicide denied ever having made this accusation:

Judge: Look, her mother-in-law and her husband mistreated her. This is all you told the police ... Did you tell the police that the accused was beating her?

Man: No, I didn't tell the police. (field notes, Shimla, 2009)

The judge then dictated in English to the stenographer:

It is incorrect that I stated to the police that the accused were beating Anjana [his daughter] or that they had ever maltreated her (confronted with portion A to A of mark A in which it is recorded). (Court file, Himachal Pradesh v. Neelam Safri \& Susheel Kumar, 2009)

It is incorrect that my daughter complained to me that the accused had started treating her with cruelty nor did I make such a statement to the police (confronted /p. 29/ with portion B to B of statement ex PW 1-A in which it is so recorded). (Court file, Himachal Pradesh State v. Neelam Safri \& Susheel Kumar, 2009)

Using a negative form of transcription 'it is incorrect that my daughter complained to me', emphasizes the fact that the witness is 
contradicting the story he had previously given to the police or that he is contradicting what the lawyer wants to suggest. In some cases lawyers make use of a double negation as in the sentence 'It is incorrect to say that I was not present in the spot' - which may sometimes prove rather confusing, even for the judge.

The prosecutor's witnesses are also cross-examined by the defence lawyer. In cases where they have turned hostile, the lawyer will simply ask them some complementary questions. This is not the case, however, for police witnesses, as lawyers will try to undermine their credibility by asking each of them very detailed questions aimed at getting them to make contradictions with their previous report or with each other's replies. Contradiction is in fact essentially used as a way of casting doubt on the credibility of the witness's story.

As soon as the defence lawyer succeeds in throwing light on some discrepancies between the police replies and their past account, the lawyer directly dictates to the stenographer a standardized sentence which enables him to highlight the discrepancy. For example, in a narcotics case, the defence lawyer wanted to put on record that the time a police officer gave during the trial regarding the call he had received from a secret informant did not match the time he had written in his report. After asking the police officer to confirm that the time given in his reply was correct the lawyer dictated to the stenographer the following sentence as if the witness was speaking in the first person; 'My today's testimony is correct, whereas the time of receipt of secret information written in seizure memo [in the report] is incorrect' (Court file, Himachal Pradesh State v. Kanshi Ram, 2010).

This sentence is the equivalent of the formula 'Confronted with' used in the case of hostile witnesses mentioned above. By emphasizing the discrepancy between the current and the previous account the defence lawyer aims to discredit the police officer's credibility in the eyes of the judge. Here, too, expressing doubt is a written procedure which is not even completely understood by the person concerned, especially those who do not speak English, who do not realize that their credibility has been challenged in the evidence report.

Another codified procedure aimed at introducing doubt about a witness's credibility is used at the end of the cross-examination and serves to elicit the reason why the witness would choose to support the accused, and thus to deny his previous statement. This is done by using 
another written formula whose effect is to affirm the very opposite of what is being denied. These conclusive sentences are dictated by the lawyer in English to the stenographer on behalf of the witness. The aim is to allow the reason why the witness may be telling lies before the court to emerge. For example, in the case where an offence is committed in a village, the village president is always included among the prosecutor's witnesses at the trial.

\section{/p. 30/}

In all the narcotic cases I followed, both in Shimla and Mandi Session Courts, the village president started to contradict what he or she was supposed to have said during the investigation. They were therefore declared hostile witnesses and subjected to cross-examination. In one case, for example, the judge, at the end of the cross-examination, told the village president in Hindi:

Judge: Look, you are protecting them because they are your supporters and you are doing this to win their votes.

Pradhan: No, they are not my supporters and I am telling the truth. (field notes, Shimla, 2010)

The judge then dictated in English to the stenographer:

It is incorrect that I [the village president] am suppressing the truth because the accused backed me in the elections (Court file, Himachal Pradesh State v. Kanshi Ram, 2010)

As in the other case mentioned above, the negative form is used here to suggest what is apparently being denied, that the village president is suppressing the truth.

Reference to the electoral link between the accused and the witness is a very typical way of concluding a hearing with a village president. It is a standard formula added at the end of the court interaction to implicitly suggest that the witness is telling a lie and to give the reason for this. In fact, most of the time the judge and the prosecutor know that as well as winning the votes of the accused the village president has received money from them. Yet, the 'electoral reason' is a conventional form of recording the fact that a village president has turned hostile.

Another common formula used when a fellow villager of the accused turns hostile to the prosecutor points to the links which 
supposedly exist between those belonging to the same village. For example, in a rape case (Himachal Pradesh State v. Devinder Sharma, 2010), the formula dictated at the end of the cross-examination was 'It is incorrect to say that I belong to the same village of the accused and that for this reason I am telling a lie' (Court file). In fact, this sentence does indeed suggest that the witness is telling a lie and that he is supporting the accused because he belongs to the same village. In another similar case the formula used was 'It is incorrect that I have received consideration from the accused and that for that reason I am telling a lie' (Court file), which suggests that the witness may have received some money or some compensation from the party of the accused in return for testifying in his favour.

This kind of conclusive sentence is also used by the defence lawyer, especially at the end of the cross-examination of police witnesses. ${ }^{12}$ For example, in the /p. 31/ narcotics case mentioned above the defence lawyer wanted to put on record that the police officers had invented a false story against the accused and that the case had not been registered in the way they described in their report. At the end of the cross-examination he dictated to the stenographer the following sentence directly in English:

It is wrong to suggest that the case has been planted upon the accused by the police. It is incorrect that I am deposing falsely (Court file, Himachal Pradesh State v. Devinder Sharma, 2010)

This final sentence is frequently added at the end of the police's cross-examination by the defence lawyer, to infer that the police officer is in fact telling a lie.

These sentences are aimed at providing the lawyer's version of the story through the witness's denial of what he appears to be stating. This is a conventional form of recording cross-examination: it enables the lawyer to suggest his version without leaving the accused the chance to react in any way. In fact this kind of sentence may even be dictated by the judge or the lawyer even though the witness has not actually been questioned.

\footnotetext{
${ }^{12}$ In fact, as independent witnesses frequently turn hostile the defence lawyer has no reason to contradict them. By contrast, police officers are often submitted to long cross-examination by the lawyer.
} 
As the examples above show, the content of these counter-stories is quite vague and points to some standardized idea such as village corporatism or, on the contrary, the existence of a personal enmity between the accused and the witness. Though conventional, these strategic counterarguments are expected to be found in the file. While in strong cases they may be completely ignored by the judge and considered to be merely the defence's discourse, in cases that are not entirely proven they will be used by the judge as additional arguments to conclude that the case has not been proven beyond reasonable doubt (that the doubt has not been lifted).

Although this procedure of recording slows down the trial, it provides a written transcription of witnesses' testimonies which will be referred to in the successive phases of the trial. Passages from these transcriptions will be read aloud by the lawyer or prosecutor during the arguments and will be quoted by the judge in his written order. They will also be used much later, when the case is examined at the appeal Court many years after the verdict. Here the appeal judge will rely entirely on these transcriptions to evaluate the case. However, unlike in the trial situation, where the witnesses' appearance, their attitudes and their replies enable the judge to evaluate the truthfulness of their words, the appeal Court can only rely on the information recorded in the file by the trial judge.

\section{The Percentage of Doubt: The Notion of 'Beyond Reasonable Doubt'}

Contrary to these interactional and strategic techniques for introducing doubt into the court file, reference to the notion of doubt is explicitly made by judges in the /p. 32/ judgments they have to write up after a hearing. Here the legal notion of 'beyond reasonable doubt' is often used by the judge to argue his final decision. Although often presented as the highest 'standard of proof' the notion of 'reasonable doubt' is not explicitly defined in legal codes of procedure (Whitman 2008) and judges often use it by making reference to a rather general meaning (or discourse) as found in other judgments, especially from appeal courts.

High Court judges in Shimla were also puzzled when I asked them to tell me the meaning of this notion. They found the question 
very pertinent and started not only to discuss it with their colleagues but also to raise the question in court. The way in which the notion of 'reasonable doubt' is used in judgments may in fact vary from one judge to another. Let us compare, for example, two judgments passed by two session judges.

The following passage is taken from a judgment concerning a narcotics case. The judge, who was known in the Shimla court milieu as an open-minded and non-convicting judge, addressed this issue as follows:

The prosecution is bound to stand on its own legs and to prove the case beyond reasonable doubt. In view of the nature of the punishment provided for by the commission of alleged offences, standard of proof is also required to be much higher and case set-up is required to be proved in a mathematical manner and beyond any reasonable doubt. (State of Himachal Pradesh v. Sanjay and others, 2007)

This may be compared to the judgment of another judge of the Mandi Session Court, who was a close friend of the previous judge, but had more traditional views and was known as a 'convicting judge'.

It is now fairly settled that there can hardly be a case with cast iron perfections in all respects ... The court should not extend exaggerated devotion to the rule of benefit of doubt or lingering suspicion. Justice cannot be made sterile on the plea that it is better to let a hundred guilty persons escape than punish an innocent person. Proof beyond reasonable doubt constitutes a guideline and vague hunches cannot take the place of judicial evaluation. (State of Himachal Pradesh v. Setu Devi, 2004)

A High Court judge from Himachal Pradesh, who was well known for being very progressive and open-minded, considered the first passage as a 'regressive' kind of reasoning. 'This is what the law was twenty years back', he told me, 'but the law evolves ... we cannot forget that witnesses in India can be bought. If independent witnesses turn hostile or if there are minor contradictions, this is not a reason to acquit the accused'. He noted how the notion of 'beyond reasonable doubt' has been subjected to historical transformations of the perception of proof. According to him, whereas twenty years ago the 
general attitude of judges was to make a ruling only if they were 100 per cent sure that the accused had committed the /p. 33/ offence, today most judges 'pass judgment even if they are only 90 per cent or 80 per cent sure', depending on the judge. He also noted how the percentage of doubt that leads a judge to decide one way or another may sometimes depend on the time that has passed since the first sentence, especially when they have to return a verdict to acquit the accused. He gave me as an example a rape case where the accused had been acquitted twenty years earlier by the trial court and for which he now had to examine the appeal. The judge thought that the decision to acquit the accused was wrong and he strongly reproached most of his colleagues for not taking the rape case seriously. However, in the case in question, he finally decided to dismiss the appeal. He explained: 'The accused has now married and has a daughter who is almost my daughter's age. If after twenty years I put him behind bars his wife would be miserable and his daughter too'. He added, however, that he would no doubt have convicted the man if it had been a case of murder.

The experience and the consequence of doubting are probably not the same for a Session judge (who conducts the trial) and an appeal Court judge. Unlike the appeal judge, who can merely rely on the court file or on the lawyer's statements, the doubt the trial judge has may increase or diminish after the judge has directly interacted with the witnesses and the accused. However, the kind of personal or intuitive opinion the judge has during the trial may sometimes be different from what he decides in his verdict because his decision must be based on the evidence that has been put on record during the hearings. ${ }^{13}$ For example, in a rape case tried in Shimla court, during out-of-court discussions the judge appeared to be convinced that the victim, a nine-year-old girl from a Scheduled caste, had been raped by the accused, a Brahman boy, son of the girl's landlord. This could also be deduced during the hearings when, on behalf of the prosecutor, the judge on many occasions dictated the formula suggesting that the prosecution witnesses, who had turned hostile in favour of the accused, were telling a lie because they had received compensation from the

\footnotetext{
${ }^{13}$ In such cases, the judgment of acquittal recorded by the trial judge sometimes appears to be in contradiction to the attitude he may have towards the prosecution witnesses at the time of the trial (accusing them of not telling the truth and of turning hostile).
} 
party of the accused. In spite of this personal opinion and of the fact that other witnesses, including the schoolteacher, supported the prosecutor, he decided to acquit the accused. He wrote in the judgment:

Confronted with the evidence discussed, finding recorded and law cited supra, this court is left with no option except to hold and conclude that the prosecution has miserably failed to prove its case beyond reasonable doubt. (Court file, Himachal Pradesh State v. Devinder Sharma, 2010)

He explained to me that, even when he thinks that the accused is guilty, he is strictly bound by the evidence required by state law. In this case, for example, even if important prosecution witnesses, such as the girl's teacher, had testified against /p. 34/ the accused, the fact that the victim and her mother denied the offence transformed the other versions into 'hearsay'.

In cases like this where the judge considers that there are obstacles to convicting the accused, the notion of 'beyond reasonable doubt' might be used by the judge in a rhetorical way, as a catch-all notion automatically invoked to justify the decision of an acquittal. Here the presence of doubt is often associated with the 'chain of evidence theory' frequently used by judges in their written decisions. What follows is a short passage of a Supreme Court judgment referring to this idea of 'chain of evidence' in a High Court decision:

There must be a chain of evidence so complete as not to leave any reasonable grounds for the conclusion consistent with the innocence of the accused and must show that in all human probability that the act must have been done by the accused. (Sharad Birdhi Chand Sarda v. State of Maharashtra, 17 July 1984)

As in the case of the mathematical certainty mentioned above by the Shimla judge, the 'chain of evidence theory' is played down by some judges who consider it possible to convict the accused even if some minor links in the chain are missing. The reasonable doubt that may prevent the judge from convicting a man may therefore vary depending on a multiplicity of factors which lead judges to present this notion as a 'doctrine' rather than as a personal or cognitive experience. 
As A.C. Dogra, a former session judge who at the time of my fieldwork was Law Secretary in the Himachal government, told me:

Each judge has his own approach to evaluating the evidence; that's why in a given case you find that the trial court will acquit the accused and then the High Court will convict the person. People may say that the trial judge has not assessed the evidence properly, that he overplayed the contradictions in the evidence. Now, the appreciation of circumstantial evidence depends on the judge's mindset. (Interview, Shimla 2011)

The technical rather than psychological nature of doubting emerges in the way a judge may try to elude - at least partly - an element of doubt in order to convict the accused. Let us take an example. In 2012 during a criminal appeal at Himachal Pradesh High Court, a two-judge bench overturned a ruling to acquit the accused that had been pronounced by a trial court in 2004 concerning a case where the two accused, a man and his mother, had been charged simultaneously under section 372 (murder) and section 498a (harassment). They were accused of having harassed their respective wife and daughter-in-law by insisting that she bring a larger dowry, of having finally killed the woman and of staging the murder as a suicide. This theory was backed by the medical report according to which the cause of death was ante-mortem internal injuries, not hanging. It was also backed by the victim's family who had testified before the court regarding the dowry demands. However, a suicide note had allegedly been found by the husband, which said that /p. 35/ none of her family should be held responsible for her suicide. This note, which a laboratory had certified as having been written by the victim, had led the trial judge to acquit the accused by giving them the benefit of the doubt. However, the appeal judges who, as one of them told me, were 'convinced that it was a case of murder' thought up a way of getting around what they admitted to be an element of doubt - the suicide note - by affirming that the woman had committed suicide as a result of the harassment inflicted on her by her husband and mother-in-law. They thus convicted the accused not of murder but of harassment and abetment to suicide. The way one of the judges on the bench explained their decision to me shows the reasoning process behind their decision: 
To be honest, if the suicide note was not there we would have sent them down for murder. Both of us were convinced in our minds that it was murder but what was standing in our way was the suicide note she had written. In fact, it may also be that the doctor had not done his job properly ... Now when there is a doubt, when a suicide note exists ... If there is a suicide note it cannot be murder. My brother (the other judge of his bench) and I, we kept discussing this matter. We discussed it many times. It took us two weeks to deliver the judgment, which is unusual in my court. So I said, OK [let it be murder], but we won't let them both get off scot-free. In the ruling we have come to the conclusion that it was not murder but suicide, and that the note was written under coercion. As there was also a case about dowry demands, we got them for a dowry death, which is seven years whatever the provision ... You see, these are cases where we have to think a lot. We thought that if we sentenced them for murder and then the suicide note worked at the Supreme Court [that is if the suicide note was again taken as an element of doubt] then they would be acquitted even for dowry death because no one will raise that issue there, so we thought it better to opt for a lesser crime. This is the way we work. ${ }^{14}$

The example shows how in this case the element of doubt, far from being a state of mind, was a technical obstacle for the judges which had to be strategically overcome. It also shows how judges may, in difficult cases, twist the case away from what they personally understand, when they are uncertain about how their decision is going to be received at the next level.

This kind of strategy that aims to find an alternative solution in order to convict the accused, even when there are technical obstacles to proving the offence, is not specific only to the court. The conversations I had with various state legal officers reveal a system that shows a similar attempt to sidestep the question of proof. According to this system, all serious criminal cases punishable by more than seven or ten years' imprisonment and which result in an acquittal by the /p. 36/ Session Court are almost systematically sent to the appeal Court. As one senior advocate General in Shimla explained to me:

\footnotetext{
${ }^{14}$ For information, the judge told me that both the accused were eventually acquitted by the Supreme Court.
} 
When I worked at the Law Department we received from the prosecutor's office so many files that we didn't have time to examine them in detail. So we used to simply say that a file had not been properly examined by the court ... In a criminal appeal it is very easy to prepare one or two pages on these grounds to file an appeal to the High Court instead of examining the case in detail. (Interview, Shimla, 2011)

This routinization of the appeal process seems to have less to do, here again, with a mental attitude than with a form of 'procedural doubt' where doubting appears to be integrated into the procedure itself. $^{15}$

\section{Concluding Remarks}

In both contexts of judgment, doubt not only has to be resolved through the (ritual or judicial) procedure: it first has to be produced and made explicit. In both cases, the process of doubting appears less as a cognitive attitude than as a technical device completely integrated into the procedural rules which may be used both as a communication strategy and as a space for producing or imposing contrasting points of view. Although in ritual consultations doubting is presented as coming from the person who has to be judged (not from the judge, as in the case of a trial), in both cases doubt is first and foremost a technique controlled by ritual or legal professionals.

In ritual consultations, management of the "verification techniques' (rice distribution, ore pogre) is a way for the person to become involved in the interpretative process and for the medium to reinforce the authority of his verdict. The technical character of doubt appears even more clearly in the context of criminal trials where

\footnotetext{
15 Behind this systematic recourse to appeal, there is also a problem of accountability, with every officer leaving the decision to the next officer. In fact, when a criminal case ends in an acquittal, the file of the case starts its journey through various offices where people have to give their opinion on whether the case should be sent for appeal. For serious offences, where the sentence is more than seven or ten years' imprisonment, the file is sent from the Home Department to the Law Secretary and then to the office that deals with criminal cases. In the event that an appeal is recommended, the file is sent to the Advocate General who represents the state at the High Court.
} 
casting doubt on the witnesses' credibility is part of the fighting spirit common to the adversarial procedure. Here the techniques of doubting (cross-examination, strategic use of the negative/affirmative in dictation) are very much aimed at casting doubt on what the witness is saying and on their credibility. Most of these techniques are not even understood by the person on whom doubt is cast /p. 37/ because they are pronounced in English and dictated directly to the stenographer. This therefore constitutes codified doubt, which is recorded in the file and is likely to be effective later on - when the (trial or appeal) judge has to write his decision.

Compared to these strategic and interactional techniques of doubting, the notion of 'beyond reasonable doubt' referred to by judges in their decisions may appear to rely on the judge's personal conscience. However, even this notion which is common to all adversarial systems seems rather far from the idea of an 'emotionally disrupting experience of doubting' as is often described in relation to the French idea of 'intime conviction', which allows the judge (and the jurors) to pronounce a person 'guilty' or 'innocent' (Bouillier, this volume). As the expression may somehow suggest, 'reasonable' doubt lays emphasis on a more weighted, rational attitude which appears to be far from the 'disquiet and uncertainty' experienced by French jurors who, in a 'contemplative silence' and 'searching for the truth deep down within themselves', are eventually and suddenly 'invaded by an intime conviction' (Cuer 2011). In comparison, 'beyond reasonable doubt', at least in the way it is used in India, appears to be the consequence of an application of formal rules, which the judge may use independently from and even in contradiction with his 'intime conviction'.

\section{References}

Beatty, Andrew (1999) Varieties of Javanese Religion: An Anthropological Account, Cambridge: Cambridge University Press.

Berti, Daniela (2009) 'Kings, gods and political leaders in contemporary India', in Bards and Mediums in the Khas Kingdoms, ed. Marie Lecomte-Tilouine, Almora: Himalayan Book Depot, pp. 107-36.

Berti, Daniela (2012a) 'Ritual faults, sins, and legal offences: a discussion about two patterns of justice in contemporary India', in Sins and 
Sinners: Perspectives from Asian Religions, ed. Phyllis Granoff and Koichi Shinohara, Leiden: Brill, pp. 153-72.

Berti, Daniela (2012b) 'Filing religion: the judicialisation of a religious conflict in Himachal Pradesh', Just-India Workshop, Religion and the Court (India, Nepal), Paris, 18-19 June 2012.

Boyer, Pascal (1990) Tradition as Truth and Communication: A Cognitive Description of Traditional Discourse, Cambridge: Cambridge University Press.

Clementin-Ojha, Catherine (2012) 'Claiming religious rights from a secular power: a judgment on the rules of succession to the charge of shebait in a North Indian temple', Just-India Workshop, Religion and the Court (India, Nepal), Paris, 18-19 June 2012.

Cuer, Roland (2011) 'Doute et subjectivité du juge' [Le Bien Commun, with Antoine Garapon, originally broadcast 2 July 2011], available at http://ww.franceculture.fr/player/reecouter?play=4270827 (accessed 24 December 2013).

\section{/p. 38/}

Granoff, Phyllis (2010) 'Justice and anxiety: false accusations in Indian Literature', Rivista di Studi Orientali 83(1-4): 377-98.

Hamayon, Roberte (2006) 'L'anthropologue et la dualité paradoxale du "croire" occidental', Revue du MAUSS 28(2): 427-48.

Højbjerg, Christian K. (2002) 'Religious reflexivity: essays on attitudes to religious ideas and practice', Social Anthropology 10(1): 1-10.

Lea, John (2006) 'The criminal court trial', available at http://www.bunker8.pwp.blueyonder.co.uk/cjs/26905.htm (accessed 24 December 2013).

Lenclud, Gérard (1990) 'Vues de l'esprit, art de l'autre. L'ethnologie et les croyances en pays de savoir', Terrain 14: 5-19.

Malik, Aditya (2010) 'In the divine court of appeals: vows before the god of justice', in Hinduism and Law: An Introduction, ed. Timothy Lubin, Donald R. Davis, Jr. and Jayanth K. Krishnan, Cambridge: Cambridge University Press, pp. 207-14.

Needham, Rodney (1972) Belief, Language and Experience, Oxford: Blackwell.

Pouillon, Jean (1993) Le Cru et le su, Paris: Seuil.

Rappaport, Roy (1999) Ritual and Religion in the Making of Humanity, Cambridge: Cambridge University Press.

Schlemmer, Grégoire (2009) 'Jeux d'esprits. Ce que sont les esprits pour les Kulung', Archives des sciences sociales des religions 145: 93-108.

Severi, Carlo (2002) 'Memory, reflexivity and belief: reflections on the ritual use of language', Social Anthropology 10(1): 23-40. 
Sontheimer, Günther-Dientz (1964) 'Religious endowments in India: the juristic personality of Hindu deities', Zeitschrift für Vergleichende Rechtswissenschaft 67: 45-100.

Vernant, Jean-Pierre (1985) 'De la présentification de l'invisible à l'imitation de l'apparence', in Mythe et pensée chez les Grecs: Études de psychologie historique, Paris: La Découverte, pp. 339-51.

Veyne, Paul (1992) Les Grecs ont-ils cru à leurs mythes?, Paris: Seuil.

Whitman, James Q. (2008) The Origins of Reasonable Doubt: Theological Roots of the Criminal Trial, New Haven and London: Yale University Press. 